\title{
Klein, Thoralf, Schumacher, Frank, Kolonialkriege. Militärische Gewalt im Zeichen des Imperialismus
}

\section{Anne Duménil}

\section{OpenEdition}

\section{Journals}

Édition électronique

URL : http://journals.openedition.org/ifha/1718

DOI : $10.4000 /$ ifha. 1718

ISSN : 2198-8943

\section{Éditeur}

IFRA - Institut franco-allemand (sciences historiques et sociales)

Référence électronique

Anne Duménil, « Klein, Thoralf, Schumacher, Frank, Kolonialkriege. Militärische Gewalt im Zeichen des Imperialismus », Revue de l'IFHA [En ligne], Date de recension, mis en ligne le 01 janvier 2008, consulté le 22 septembre 2020. URL : http://journals.openedition.org/ifha/1718 ; DOI : https://doi.org/10.4000/ ifha. 1718

Ce document a été généré automatiquement le 22 septembre 2020.

(C)IFHA 


\title{
Klein, Thoralf, Schumacher, Frank, Kolonialkriege. Militärische Gewalt im Zeichen des Imperialismus
}

\author{
Anne Duménil
}

Respectivement sinologue et spécialiste de l'histoire contemporaine des États-Unis, T.K. et F.S. présentent les actes d'un colloque organisé en janvier 2003 à Erfurt. Proposant d'examiner dans une perspective comparatiste les conflits coloniaux au XIXe et au XXe s., ils suggèrent en introduction un cadre problématique, respecté par la plupart des auteurs, qui s'articule autour de quatre axes : l'analyse des conditions et du déroulement des conflits, le « visage de la guerre » qui, sous la tutelle de John Keegan, suggère une approche $\mathrm{du}$ fait guerrier mêlant l'histoire militaire - ici souvent rigoureuse - et l'étude des modalités concrètes de mise en œuvre de la violence et des gestes de la cruauté, l'analyse des discours sur la guerre qui explore notamment les stratégies de légitimation et de contestation, enfin la mémoire de la guerre. Le procédé peut générer à la lecture une impression de monotonie mais il confère à l'ouvrage une forte cohérence et permet d'opérer des rapprochements, souvent instructifs : une tâche malheureusement abandonnée au lecteur, faute d'une conclusion permettant de dépasser une approche parfois un peu monographique du sujet - même si ces différentes études de cas, telle la riche synthèse de D. Mollenhauer sur la guerre d'Algérie, sont en elles-mêmes fort intéressantes. La carence est regrettable, un des enjeux du livre étant de dégager une définition du concept de guerre coloniale et d'affiner la compréhension de sa place « sur le chemin de la guerre totale ».

La proposition des auteurs est de désenclaver la notion de guerre coloniale au temps des impérialismes, en ne la limitant pas aux guerres de conquêtes ou aux conflits outremer. Le rapprochement des deux communications consacrées à l'histoire coloniale des États-Unis au XIXe s. - l'excellent article de M. Hochgeschwender consacré aux « guerres indiennes dans l'Ouest des États-Unis (1840-1890) » et la contribution de F. Schumacher sur la guerre des Philippines (1899-1913) - peut convaincre de la pertinence de l'approche. Celle-ci parait moins nette lorsque d'autres conflits sont abordés : la guerre des Boxers (T.K.) offre un cas limite mais l'approche ne convainc 
guère dans l'article sur la guerre des Boers (C. Eberspächer). Elle parait forcée lorsqu'il s'agit d'étudier la guerre sino-japonaise (1931-1945) (R. Zöllner) : sans contester la dimension impérialiste de la guerre conduite par le Japon en Asie, est-il pour autant pertinent d'analyser toute politique expansionniste en termes d'ambition coloniale ? L'attention portée au rôle du soutien américain à la Chine à partir de 1941 manifeste bien à quel point il est impossible d'isoler le conflit sino-japonais du contexte de la Seconde Guerre mondiale. Placée en début de volume, la contribution de D. Walter, " Pourquoi la guerre coloniale ? " ne permet pas, même relue a posteriori, de lever les ambiguïtés nées d'une définition trop extensive de l'objet étudié. Dans la continuité suggérée entre les guerres coloniales et les conflits les plus contemporains (Irak, Afghanistan) ou dans l'idée de la guerre coloniale toujours recommencée sous d'autres masques, on verra la marque d'une difficulté à penser la nature d'une conflictualité finalement peut-être moins particulière, plus banale au sens où ces conflits participent finalement du fait guerrier contemporain. Plusieurs articles relèvent ainsi la porosité entre les guerres coloniales et les autres conflits : la guerre d'Indépendance forme ainsi une césure de l'histoire des guerres indiennes, la guerre du Rif étudiée par U. Mücke constitue le creuset des formes de violence à l'œuvre lors de la guerre d'Espagne et la guerre d'Ethiopie (G. Brogni Künzi) s'inscrit dans la continuité de la totalisation des formes de violence de la Grande Guerre.

Enfin, et c'est certainement un des riches apports du volume, plusieurs articles livrent des remarques convergentes relevant d'une véritable anthropologie de la guerre : la proximité entre activité guerrière et chasse, le franchissement de seuil que constitue la mise à mort des femmes et des enfants, les pratiques de massacre (de part et d'autre), les spécificités liées aux caractéristiques de l'environnement - leur observation permet à $\mathrm{S}$. Kuss de fines distinctions entre les modalités d'exercice de la violence par les troupes coloniales allemandes engagées en Afrique du Sud-Ouest (1904-1907) et en Afrique orientale (1905-1908). Saisies ici au prisme du rapport de domination coloniale, parfois corrélées trop étroitement aux seules représentations racistes, ces analyses gagneraient à être mises en relation plus systématiquement avec les observations relevées sur d'autres fronts : en cela, ce volume promet d'enrichir notre compréhension de la violence de guerre.

Anne Duménil (Lycée français de Munich) 